Appeared in: European Journal of Operational Research, 180(2), 2007, 738--753.

SCHOOL OF BUSINESS WORKING PAPER No. 302

\title{
Using Bayesian Networks for Bankruptcy Prediction: Some Methodological Issues
}

\author{
Lili Sun ${ }^{*}$ \\ and \\ Prakash P. Shenoy $^{* *}$
}

July 2004

Revised February 2006

\footnotetext{
${ }^{*}$ Lili Sun, Assistant Professor, Accounting and Information Systems, Rutgers Business School, Ackerson Hall, Room 317, 180 University Ave., Newark, NJ 07102-1897. Email: sunlili@rbsmail.rutgers.edu

** Prakash P. Shenoy, Ronald G. Harper Distinguished Professor of Artificial Intelligence, School of Business, University of Kansas, 1300 Sunnyside Ave., Lawrence, KS 66045-7585. Email: pshenoy@ku.edu
} 


\title{
Using Bayesian Networks for Bankruptcy Prediction
}

\begin{abstract}
This study provides operational guidance for using naïve Bayes Bayesian network (BN) models in bankruptcy prediction. First, we suggest a heuristic method that guides the selection of bankruptcy predictors from a pool of potential variables. The method is based upon the assumption that the joint distribution of the variables is multivariate normal. Variables are selected based upon correlations and partial correlations information. A naïve Bayes model is developed using the proposed heuristic method and is found to perform well based upon a tenfold analysis, for both samples with complete information and samples with incomplete information. Second, we analyze whether the number of states into which continuous variables are discretized has an impact on a naïve Bayes model performance in bankruptcy prediction. We compare the model's performance when continuous variables are discretized into two, three, ..., ten, fifteen, and twenty states. Based upon a relatively large training sample, our results show that the naïve Bayes model's performance increases when the number of states for discretization increases from two to three, and from three to four. Surprisingly, when the number of states increases to more than four, the model's overall performance neither increases nor decreases. It is possible that the relative large size of training sample used by this study prevents the phenomenon of over fitting from occurring. Finally, we experiment whether modeling continuous variables with continuous distributions instead of discretizing them can improve the naïve Bayes model's performance. Our finding suggests that this is not true. One possible reason is that continuous distributions tested by this study do not represent well the underlying distributions of empirical data. More importantly, some results of this study could also benefit the implementation of naïve Bayes models in business decision contexts other than bankruptcy prediction.
\end{abstract}

Key words: bankruptcy prediction; Bayesian networks; naïve Bayes; selection of predictors; discretization of continuous variables 


\title{
Using Bayesian Networks for Bankruptcy Prediction: Some Methodological Issues
}

\begin{abstract}
This study provides operational guidance for building naïve Bayes Bayesian network (BN) models for bankruptcy prediction. First, we suggest a heuristic method that guides the selection of bankruptcy predictors. Based on the correlations and partial correlations among variables, the method aims at eliminating redundant and less relevant variables. A naïve Bayes model is developed using the proposed heuristic method and is found to perform well based on a ten-fold validation analysis. The developed naïve Bayes model consists of eight first-order variables, six of which are continuous. We also provide guidance on building a cascaded model by selecting second-order variables to compensate for missing values of first-order variables. Second, we analyze whether the number of states into which the six continuous variables are discretized has an impact on the model's performance. Our results show that the model's performance is the best when the number of states for discretization is either two or three. Starting from four states, the performance starts to deteriorate, probably due to over-fitting. Finally, we experiment whether modeling continuous variables with continuous distributions instead of discretizing them can improve the model's performance. Our finding suggests that this is not true. One possible reason is that continuous distributions tested by the study do not represent well the underlying distributions of empirical data. Finally, the results of this study could also be applicable to business decision-making contexts other than bankruptcy prediction.
\end{abstract}

Key words: bankruptcy prediction; Bayesian networks; naïve Bayes; variable selection; discretization of continuous variables 


\section{INTRODUCTION}

In today's dynamic economic environment, the number and the magnitude of bankruptcy filings are increasing significantly. Even auditors, who have good knowledge of firms' situations, often fail to make an accurate judgment on firms' going-concern conditions (e.g., Hopwood et al. 1994; McKee 1998, 2003). Therefore, bankruptcy prediction models have become important decision aids for organizations' stakeholders, including auditors, creditors, and stockholders.

Techniques employed to develop bankruptcy prediction models have evolved from the simple univariate analysis (Beaver 1966) and multiple discriminant analysis (MDA) (Altman, 1968) in the 1960s, to logit and probit models in the 1980s (Ohlson 1980, Zmijewski 1984), to neural network models (NN) (Tam and Kiang 1992), rough set theory (McKee 1998), discrete hazard models (Shumway 2001), Bayesian network (BN) models (Sarkar and Sriram 2001), and genetic programming (McKee and Lensberg 2002). Among these techniques, BN models have many attractive features. They are easy to interpret, perform well as a classification tool, have no restriction on variables' underlying distributions, and have no requirement of complete information.

In order to allow a formal Bayesian model to become useful decision aids, adequate operational guidance needs to be provided (Senetti 1995). Although some prior work (e.g., Sarkar and Sriram 2001; Kotsiantis et al. 2005) have introduced BNs to bankruptcy predicting, there is still a lack of proper guidance in the selection of variables and the discretization of continuous variables. This study attempts to fill this void. This study focuses on one type of BN models: naïve Bayes, which are simple to implement and have been shown to perform well in bankruptcy prediction (Sarkar and Sriram 2001). First, there exists a large pool of potential bankruptcy predictors, including various financial ratios, stock market information, industry 
level factors, etc. A method is needed to guide the selection of variables that can be used to develop a well-performing naïve Bayes BN for bankruptcy prediction. This work proposes such a heuristic method based on the assumption of linear dependence as measured by correlations between variables. Grounded on existent feature selection literature (e.g., Koller and Sahami 1996), the proposed method aims at identifying key predictors and eliminating redundant or irrelevant ones. Secondly, BN models generally use discrete-valued variables. Through discretization, continuous variables are converted into discrete variables with several states. It is unclear whether and how the number of states into which continuous variables are discretized have an impact on BN models' performance. This study explores this issue. The study further examines whether modeling continuous variables with continuous distributions instead of discretizing these variables can improve the model's performance.

The remainder of this paper is organized as follows. Section 2 provides a literature review on bankruptcy prediction techniques. In section 3, we discuss the probabilistic concepts underlying BN models. In section 4, we describe our sample and data. Section 5 describes research process and present results. Section 6 summarizes and concludes the paper.

\section{LITERATURE REVIEW}

In this section, we briefly review some techniques employed to develop bankruptcy prediction models in prior research and discuss the advantages of $\mathrm{BN}$ as a classification tool.

Different methods have been implemented in developing bankruptcy prediction models. Beaver (1966) used univariate analysis to compare patterns of 29 ratios in the five years preceding bankruptcy, for a sample of failed firms, with a control group of firms that did not fail. During the late 1960s and throughout the 1970s, multiple discriminant analysis (MDA) was used to develop bankruptcy prediction models. Two of the well-known bankruptcy prediction models, 
Altman's Z-score (Altman 1968) and ZETA (Altman et al. 1977) were developed using MDA. Beginning in the 1980s more advanced estimation methods, such as logit (Ohlson 1980) and probit (Zmijewski 1984), were employed.

During the 1990s, the neural network (NN) model was introduced into bankruptcy prediction. Research has shown contradictory results regarding NN's superiority over linear models (Altman et al. 1994; Tam and Kiang 1992). Later on, Sarkar and Sriram (2001) developed Bayesian network (BN) models for early warning of bank failures. They found that both a naïve $\mathrm{BN}$ model and a composite attribute $\mathrm{BN}$ model have comparable performance to the well-known induced decision tree classification algorithm. Some other techniques, such as rough set theory (McKee 1998), discrete hazard models (Shumway 2001), and genetic programming (McKee and Lensberg 2002), have also been introduced to the bankruptcy prediction area.

Prior research has shown that BNs perform well as a classification and prediction tool in different domains (see e.g. Clark and Niblett 1989; Langley et al. 1992; Pazzani et al. 1996; Sarkar and Sriram 2001; Anderson et al. 2004). Unlike most regression techniques, BNs do not have any requirements on the underlying distributions of variables. BNs can easily model complex relationships among variables including partial mediators and "interaction effects". BNs do not require complete information for observations. Observations that have some missing variables can still be used to train or test $\mathrm{BN}$ models. This is very important for bankruptcy studies because bankruptcy samples are usually small and bankrupt firms tend to have missing information. BNs are dynamic and interactive. They can easily be updated with new information as it is learned. Subjective human knowledge can easily be incorporated into models. Compared to other machine learning techniques, such as neural networks, BN models are more transparent and intuitive because relationships among variables are explicitly represented by the direct 
acyclic graph. Users report that BNs' representations are quite intuitive and easy to understand (Kononenko 1990).

\section{BAYESIAN NETWORK MODELS}

Bayesian networks $(\mathrm{BN})$ are probabilistic graphical models that represent a set of random variables for a given problem, and the probabilistic relationships between them. The structure of a $\mathrm{BN}$ is represented by a direct acyclic graph (DAG), in which the nodes represent variables and the edges express the dependencies between variables (Pearl 1988). The probabilistic part of the $\mathrm{BN}$ is represented by a set of conditional probabilities. Next, we discuss the basic concepts of BN models in the context of bankruptcy prediction.

\subsection{Bayes Rule}

Bayes rule can be expressed as follows:

$$
P(A \mid B)=\frac{P(B \mid A) P(A)}{P(B)}
$$

In a bankruptcy prediction context, this can be interpreted as follows. Suppose we are interested in event $A$, which represents a company's bankruptcy filing. We start with a prior probability $P(A)$, representing out belief about $A$ before observing any relevant evidence. For instance, $P(A)$ can be measured as the mean percentage of firms in the whole population that have declared bankruptcy in the past. $P(B \mid A)$ represents the likelihood for bankruptcy based on observing a bankruptcy predictor $B$ such as a late $10-\mathrm{K}$ filing. $P(B)$, the probability of a firm filing its 10-K late, is just a normalizing constant. Suppose we observe $B$. By Eq. (1), our revised belief for the probability of bankruptcy, the posterior probability $P(A \mid B)$, is obtained by multiplying the prior probability of bankruptcy $P(A)$ by the likelihood $P(B \mid A)$ and then normalizing the result by dividing by the constant $P(B)$. 
Eq. (1) can be rearranged into Eq. (2), which states that the posterior odds for $A$ equals the prior odds for $A$ multiplied by the likelihood ratio for $A$ from evidence $B$, i.e.,

$$
\frac{P(A \mid B)}{P(\sim A \mid B)}=\frac{P(A)}{P(\sim A)} \frac{P(B \mid A)}{P(B \mid \sim A)}
$$

where $\frac{P(B \mid A)}{P(B \mid \sim A)}$ represents the likelihood ratio for $A$ from evidence $B$.

Based on the graphical structure of a BN model, it can be classified as a naïve Bayes, a tree augmented naïve Bayes, a general BN, etc. The present study focuses on the naïve Bayes model because it is simple to implement and have been shown to perform well in bankruptcy prediction (Sarkar and Sriram 2001). Next, we further discuss the naïve Bayes model.

\subsection{A Naïve Bayes Bayesian Network Model}

The naïve Bayes BN model is named by Titterington et al. (1981) because of its simplicity. Figure 1 presents a graphical representation of a naïve Bayesian network model.

Insert Figure 1 Here

In a naïve Bayes model, the node of interest has to be the root node, which means, it has no parent nodes. In a bankruptcy prediction context, in Figure 1, $A$ represents the bankruptcy variable. $B_{1}, B_{2} \ldots, B_{n}$ represent $n$ bankruptcy predictor variables. The naïve Bayes model assumes the following conditional independence:

$$
B_{i} \perp\left\{B_{1}, B_{2}, \ldots, B_{i-1}, B_{i+1}, \ldots B_{n}\right\} \mid A, \text { for } i=1,2, \ldots, \mathrm{n} .
$$

The above assumption says that predictors, $B_{1}, B_{2} \ldots, B_{n}$ are conditionally mutually independent given the state of bankruptcy. Based on this conditional independence assumption, the posterior odds of $A$ can be expressed as: 


$$
\frac{P(A \mid B)}{P(\sim A \mid B)}=\frac{P(A)}{P(\sim A)} \times \prod_{i=1}^{n} \frac{P\left(B_{i} \mid A\right)}{P\left(B_{i} \mid \sim A\right)}
$$

In the expression (3) above, $B$ represents a vector of observations $\left(B_{1}, \ldots, B_{n}\right)$. If only $k$ of $n$ predictors were observed, then the posterior odds for $A$ is given by an equation similar to (3) above where only the likelihood ratios from the $k$ predictors are used (instead of all $n$ predictors as in (3)). The predictors that are not observed have no effect on the posterior odds for $A$.

\section{SAMPLE AND DATA}

Sample firms used in this study are publicly traded firms on major stock exchanges (NASDAQ, the New York and American Stock exchanges) across various industries during the period 19892002. We do not impose any selection restriction on the size or industry characteristics when forming bankrupt and non-bankrupt samples. The following steps are used to identify bankrupt ${ }^{1}$ firms. First, bankrupt firms are identified through Compustat and Lexis-Nexis Bankruptcy Report databases. Next, bankruptcy filing dates are identified through searching the Lexis-Nexis Bankruptcy Report library, Lexis-Nexis News, and firms' Form 8-K reports. Firms without available bankruptcy filing dates are eliminated. For each bankrupt firm, the most recent annual report filed prior to its bankruptcy filing date is identified. The lag between the fiscal year-end of the most recently filed annual report and bankruptcy filing date must be less than 2 years ${ }^{2}$. The above procedure results in 890 bankrupt firms. The nonbankrupt sample is formed as described

\footnotetext{
${ }^{1}$ The bankrupt sample in this study consists of firms that file bankruptcy petitions under both Chapter 11 and Chapter 7.

${ }^{2}$ Similar to Begley et al. (1996), we use this requirement to ensure the data used for prediction are reasonably current.
} 
below. First, we identify all active ${ }^{3}$ firms available in Compustat for each sample year of 89-02. Then we randomly select 500 firms from the identified active-firm-pool for each sample year. Once a non-bankrupt firm is selected for a year, it is excluded from selection in later years. Thus, for 14 sample years (1989-2002), we end up with 7,000 active firms as the initial nonbankrupt sample. Among these 7,000 firms, 63 firms have missing information on all 20 potential predictors and are deleted. Therefore, 6,937 firms are used to examine the correlations among variables. Further, another 5 firms have missing information on all the eight variables selected. Therefore 6,932 active firms are used to train and test the developed naïve BN models. Through our own analysis and reviewing past research (e.g., Emery and Cogger 1982; Hopwood et al. 1989; Altman 1968; Ohlson 1980; Hopwood et al. 1994; Shumway 2001; McKee and Lensberg 2002), 20 variables $^{4}$ are identified as potential bankruptcy predictors. These variables are financial-accounting factors measuring firms' size, liquidity, leverage, turnover, and profitability, market-based factors including market capitalization and abnormal stock returns, and other factors including auditors' opinions and industry failure rate. All variables for bankrupt firms are calculated based upon the most recent available data prior to firms' bankruptcy filings. Table 1 provides definitions of all variables. Table 2 provides descriptive statistics and univariate analysis of variables. Table 3 describes the average annual

\footnotetext{
${ }^{3}$ Compustat considers a firm as active as of the end of the year if it has a closing market price for December of the year.

${ }^{4}$ The 20 variables are not exhaustive and there are other useful bankruptcy variables we are not able to incorporate in this study. The proposed heuristic method of variable selection is applicable to any number of potential variables.
} 
industry failure rate ${ }^{5}$ during the study period. The categorization of industries is based on Barth et al. (1998).

\section{Insert Table 1-3 Here}

Insert Table 1-3 Here

\section{RESEARCH PROCESS AND RESEARCH RESULTS}

\subsection{A Heuristic Method for Variable Selection in Naïve Bayes Models}

There exists a large pool of bankruptcy predictors. An appropriate selection of a subset of variables is necessary for developing a useful naïve Bayes model. Koller and Sahami (1996) elaborate the importance of feature (variable) selection. First, the computation time grows dramatically as the number of features increases. Secondly, over-fitting problems occurs when we attempt to apply a large number of features to limited data available. Thirdly, irrelevant and redundant features may confuse the learning algorithm and obscure the predictability of truly effective variables. Therefore, a small number of predictive variables are preferred over a very large number of variables including irrelevant and redundant ones.

One purpose of this paper is to provide a heuristic method to guide the selection of variables in naïve Bayes models. Grounded on prior feature selection literature (e.g., Koller and Sahami 1996), the goal is to eliminate variables that provide little or no additional information beyond that subsumed by the remaining variables. To achieve the goal, the proposed heuristic relies on correlations and partial correlations among variables. This heuristic is based on the

\footnotetext{
${ }^{5}$ When calculating annual industry failure rate, we assume that the instances of bankruptcies identified in this study represent the number of bankruptcies in the real population, and the number of active firms in Compustat represents the number of nonbankruptcies in the real population.
} 
assumption that the dependence between every pair of variables is linear ${ }^{6}$ and measured by the correlation coefficient.

Next, we describe how the proposed heuristic works. First, we obtain the correlations among all variables, including 20 potential predictors and the variable of interest, firms' bankruptcy status. Variables that have significant correlations (Pearson correlation coefficient $\geq$ 0.10) are assumed to be dependent and therefore connected. We use the cutoff of $0.10^{7}$ to help identify a small subset of most important predictors while excluding the unimportant ones. Ideally, only the training sample should be used to obtain the correlation coefficient information. However, this study uses a ten-fold analysis that requires ten training samples. It is too timeconsuming to analyze the correlation coefficients among all the ten training sample. Therefore, the correlations are obtained using the entire (both training and test) sample of 7,827 firms, including 6,937 non-bankruptcies and 890 bankruptcies. Figure 2 shows the dependencies among the variables.

Insert Figure 2 Here

In Figure 2, eight predictors, $L M, C H N, I T, M, A U, R, I F R$, and $C H$ are connected with $B$ (bankruptcy status), since they have dependency (correlations $\geq 0.10$ ) with $B$. Among these eight predictors, thirteen pairs of variables have dependency (correlations $\geq 0.10$ ) within the pair. To avoid double counting information, we analyze whether one variable is dependent with $B$ given

\footnotetext{
${ }^{6}$ Note that this assumption is imposed by the proposed heuristic method for variable selection, not by the BN model itself.

${ }^{7}$ Since there is no established cutoff, we experimented with cutoffs of $0.05,0.1,0.15$, and 0.2 . The cutoff of 0.1 is the one that leads to the best prediction ability, with the least number of variables. The choice of an optimal cutoff is itself a research issue, which is not covered in this paper.
} 
the other variable in the pair by examining the partial correlations between that variable and $B$, while controlling the other variable in the pair. These partial correlations are presented in Panel A of Table 4.

Insert Table 4 Here

In Panel A of Table 4, pair 1 is $C H$ and $L M$. The significant partial correlation between $B$ and $C H(-0.10)$ given $L M$ suggests that $C H$ has incremental contribution in predicting $B$ beyond $L M$; the significant partial correlation between $B$ and $L M(-0.13)$ given $C H$ suggests that $L M$ has incremental contribution in predicting $B$ beyond $C H$. Therefore, both $C H$ and $L M$ are kept in the model. Similarly, within each of the rest 12 pairs, one variable has incremental contribution in predicting $B$ given the other variable in the pair because all partial correlations are significant (correlations $\geq 0.10$ ). Therefore, no variable is eliminated. The structure of the naïve Bayes with the eight selected variables, $L M, C H N, I T, M, A U, R, I F R$, and $C H$ is shown in Figure 3 . The model consists of financial accounting factors, market variables, auditors' opinions, and industry failure rate.

Insert Figure 3 Here

The naïve Bayes model is typically used with discrete-valued data. Prior research (e.g., Sarkar and Sriram 2001) has used bracket median method for discretization, which divides the continuous cumulative probability distribution into $n$ equally probable intervals. For the demonstration of the proposed heuristic method, we adapt the extended Pearson-Tukey (EP-T) method (Keefer and Bodily 1983), a method of three-point approximations, to convert continuous variables into discrete. Under the EP-T method, a continuous distribution is 
approximated by a discrete distribution with probabilities $0.185,0.63$, and 0.185 . Compared to bracket median method, the EP-T is able to better capture the tails of continuous variables. This feature is very suitable for the context of bankruptcy prediction since soon-to-be bankrupt firms tend to have values at the tails of the distributions (e.g. unusually high profit (McKee and Lensberg 2002), unusually high leverage, unusually low cash flow, etc.). Besides, according to Keefer (1994), the EP-T method is one of those three-point discrete-distribution approximations that accurately represent certainty equivalents for continuous random variables.

To stay in the sample for training and testing the naïve BN model, a firm needs to have at least one variable available among the eight selected children nodes. Thus, the maximum sample size for this stage of the study is 7,822, including 6,932 non-bankruptcies and 890 bankruptcies. Ideally, only data in the training sample should be used to identify the points. However, this ideal procedure requires a lot of repetitive work given the ten training samples used under the ten-fold analysis. Therefore, for each of children nodes in the naïve Bayes model of Figure 3, we use the entire (including both training and test) sample of 7,822 firms to identify two points, $x_{1}, x_{2}$, which are respectively at 18.5 percentile, and $81.5(18.5+63)$ percentile. These two points, $x_{1}$ and $x_{2}$, are used as cutoffs to determine to which status, 'High', 'Medium', or 'Low', a certain variable value should belong. A firm is assigned a status of 'Low' for the variable if it has a value smaller than $x_{1}$; a status of 'Medium' if it has a value between $x_{1}$ and $x_{2}$, and a status of 'High' if it has a value larger than $x_{2}$. Since we estimate two conditional distributions for each predictor variable, one conditioned on bankruptcy and one conditioned on non-bankruptcy, there is no bias introduced by the fact that the sample proportion of bankruptcies $(11.4 \%)$ in this study is larger than the population proportion of bankruptcies. 
To make the test results more robust, a ten-fold analysis is employed. This means that the entire sample (including bankrupt and non-bankrupt sample) is divided randomly into ten equal sized subsets. Each time, nine subsets are randomly selected to form the training sample to learn the probabilities parameters; the remaining subset is used as the test sample to test the model's performance. On an average, each training sample consists of 801 bankruptcies and 6,239 nonbankruptcies; each test sample consists of 89 bankruptcies and 693 non-bankruptcies.

Models with probabilities parameters learned from training samples are used to predict the status of bankruptcy for firms in the test sample. When testing the model, we ignore the prior since the sample proportion of bankruptcies is larger than the population proportion (e.g., McKee and Greenstein 2000). If a firm's posterior likelihood of bankruptcy given values of observed predictors is larger than 1 , it is predicted as bankrupt, otherwise nonbankrupt. The predicted results are checked for accuracy with actual statuses of firms' bankruptcy status. Table 5 reports models' prediction ability in ten test samples.

Insert Table 5 Here

On an average, the naïve BN model with eight selected variables accurately predicts $81.12 \%$ of bankruptcies, and $81.85 \%$ of non-bankruptcies. For comparison, we also obtain the prediction ability of the naïve model with all twenty potential variables (without any selection), listed on the right side of Table 5. The naïve model with all variables, on an average, correctly predicts $81.57 \%$ of bankruptcies, and $81.78 \%$ of non-bankruptcies. To conduct statistical tests of significance in models' performance differences, we assume the prediction rate (of the 10 fold results) to be normally distributed with the same variance. Thus, test of significance in the average rate between models after ten-fold analysis is equivalent to testing for difference of 
means of normal distribution. Untabulated T-test results suggest that there is no significant difference in two models' performance. This indicates that our proposed heuristic of variable selection has successfully eliminated redundant and less relevant variables, and achieved an equivalent level of performance with much fewer variables.

Appendix A presents the tables of conditional probabilities ${ }^{8}$ underlying the Naïve BN model in Figure 3. These conditional probabilities are informative in regard to the relationships between B (bankruptcy status) and its predictors. For instance, the probability of having a low $\mathrm{M}$ (market capitalization) given B is $44 \%$, which is much higher than that $(15 \%)$ given NB (nonbankruptcy).

\subsection{Missing Information and Second-order Variables}

Some sample firms have missing values on one or multiple children nodes used in Figure 3. Specifically, among the entire sample of 7,822 firms, 1,678 firms have missing value on child node $I T ; 2,419$ firms have missing values on $M ; 1,537$ firms missing on $A U ; 2,331$ firms missing on $R$; 964 firms missing on IFR; 5,345 firms missing on $L M$; 1,086 firms missing on $C H, 1,679$ missing on $C H N$. In the following discussion, we call the eight children nodes in Figure 3 firstorder variables. Next we discuss how to identify second-order variables to compensate for the missing information among first-order variables. Conceptually, second-order variables are those that have significant correlations with first-order variables and therefore are expected to provide information on the missing values of first-order variables. To select a given first-order variable's second-order variables, we follow the similar method used to select first-order variables. The

8 The conditional probabilities are learned based upon each set of training sample for each fold of analysis.

Conditional probabilities presented in Appendix A are learned from one set. Conditional probabilities learned from each of the other nine sets are substantially similar to those in Appendix A. 
major difference is that now we consider each first-order variable instead of $B$ as a root variable. Next we explain how each first-order variable's second order variables are selected.

To select second-order variables for $\mathrm{CH}$, we identify those non-first-order variables that are connected to $\mathrm{CH}$ in Figure 2. These variables have significant correlations with $\mathrm{CH}$. Such variables include $O F, C R, C S, T A, C A, S$. Among these variables, there are ten pairs of significant relationships. Next we examine the partial correlation between one variable with $\mathrm{CH}$ after controlling for the other variable in the pair (Pair 14-23, Panel B.1 of Table 4). For the pair of $O F$ and $C R$ (Pair 14), $C R$ has a significant ( $\geq 0.10$ ) partial correlation with $C H$, given $O F$, but $O F$ does not have a significant partial correlation with $C H$, given $C R$. This indicates that $O F$ does not have significant incremental contribution in predicting $C H$ beyond $C R$, therefore, $O F$ is deleted. Similarly, for the pair of $C R$ and $C S$ (Pair 17), CS is eliminated. Partial correlations among all other pairs are significant. Therefore, no other variable is deleted. To summarize, $\mathrm{CH}$ has four second-order variables, which are, $C R, T A, C A, S$.

Non-first-order variables that have significant correlations with $L M$ include $C R$, and $S$. Since there is a significant correlation between $C R$ and $S$, we obtain the partial correlation between $L M$ and $C R(S)$ given $S(C R)$ (Pair 24, Panel B.3 of Table 4). $C R$ has a significant partial correlation with $L M$, given $S$, but $S$ does not have a significant partial correlation with $L M$ after controlling for $C R$. Therefore, $S$ is deleted. $L M$ 's second-order variable is $C R$. Non-first-order variables that have significant correlations with $I T$ include $T A$, and $O F$. Since there is a significant correlation between $T A$ and $O F$, next we examine the relevant partial correlations (Pair 25, Panel B.3 of Table 4). Neither of the partial correlations is significant. In such case, the one with the higher partial correlation is selected while the one with the lower partial correlation is deleted. Therefore, $O F$ is deleted. $I T$ 's second-order variable is $T A$. 
Non-first-order variables that have significant correlations with $M$ include $O F, T A, C A, E$, $N T$, and $R E$. There exist significant correlations between $T A$ and $O F, O F$ and $C A, T A$ and $C A, T A$ and $E, T A$ and $N T, T A$ and $R E, E$ and $N T, R E$ and $E, R E$ and $N T$. To avoid double counting information, next we examine the partial correlation between one variable with $M$ after controlling for the other variable in the pair. The partial correlations are presented in Panel B.4 (Pair 26-34). For the pair of $O F$ and $T A$ (Pair 26), $T A$ has a significant $(\geq 0.10)$ partial correlation with $M$, given $O F$, but $O F$ does not have a significant partial correlation with $M$, given $T A$. Therefore $T A$ is selected, while $O F$ is deleted. Similarly, for the pair of $R E$ and $T A$ (Pair 31), $R E$ is deleted; for the pair of $N T$ and $E$ (Pair 32), $N T$ is eliminated. Partial correlations among other pairs are all significant, which does not suggest elimination of any other variable. To summarize, $M$ 's second-order variables include $T A, C A, E$.

Only one non-first-order variable, $E$, has a significant correlation with $R$. Therefore, $E$ is the second-order variable for $R$. Similarly, $S$ is the second-order variable for IFR; $C A$ is the second-order variable for $A U$. There are no non-first-order variables that have significant correlations with $C H N$. Therefore, $C H N$ has no second-order variables. By incorporating selected second-order variables into the naïve Bayes model in Figure 3, we form the following cascaded naïve Bayes model shown in Figure 4.

Insert Figure 4 Here

Using the ten-fold analysis, we obtain the average prediction performance of the cascaded naïve Bayes model as presented in Panel A of Table 6. The cascaded BN model accurately predicts $81.12 \%$ of bankruptcies and $80.08 \%$ of nonbankruptcies. T-test results suggests that, compared to the naïve model with only eight first-order variables, the cascaded 
model has indifferent prediction ability in predicting bankruptcy, but has a significantly $(p<$ $0.05)$ worse performance in predicting nonbankruptcy.

It is possible that for the full sample, the above comparison result is affected by the performance of those instances for which missing information on first-order variables is not that much. Take an extremely case in which the sample has complete information on all eight firstorder variables, the performance of the cascaded model would be identical to the naïve model because adding second-order variables does not make any difference given the Markov properties of BNs. To better examine whether the cascaded model is able to compensate for missing values on first-order variables, next, we identify firms with missing values on at least 2 first-order variables ${ }^{9}$ and redo the comparison between the cascaded model and the naïve model. In our sample, 265 bankruptcies and 3,501 nonbankruptcies qualify for such a selection. Given the reduced sample size, we perform five-fold analysis instead of ten-fold analysis here. T-test results (Panel B of Table 6) suggests that, compared to the naïve model, the cascaded model performs the same in predicting bankruptcy, while still performs significantly $(p<0.05)$ worse in predicting nonbankruptcy. Overall speaking, we do not observe significant improvement on the model's performance after adding the second-order variables. From this perspective, the naïve Bayes model presented in Figure 3 becomes more appealing with fewer variables and equivalent performance. Nevertheless, our results do not deny the possible superiority of the cascaded model over the naïve model in situations where missing information on first-order variables are even more substantial.

Insert Table 6 Here

\footnotetext{
${ }^{9}$ The verification would be more appropriate if we select firms with missing values on more than 2 first-order variables, for instance 3, or more. However, this is not doable in our sample because the number of bankrupt firms in our sample which have missing values on at least 3 first-order variables is very few.
} 


\subsection{Number of States for Discretization}

Bankruptcy prediction often involves continuous random variables. To apply these continuous variables to $\mathrm{BN}$ models, past research usually employs a discretization approach (Sarkar and Sriram 2001). This approach converts continuous variables into discrete variables with limited states, often two. During the discretization process, one problem that researchers face is to decide the number of states for discretization. Does the number of states chosen for discretization impact models' prediction power? In this study, we empirically examine this issue. The advantage of increasing the number of states is to reduce the information loss during the discretization process. However, more states require more parameters to define models. Unless one has either data or knowledge to estimate these parameters, one can easily succumb to overfitting resulting in degradation in performance.

We use the naïve Bayes model in Figure 3 to test the effect of discretization states. In the naïve Bayes model, six continuous variables, $M, R, I F R, C H, L M, C H N$, are discretized into various states, from $2,3,4, \ldots, 10$. Since bankrupt firms tend to have extreme values that reside in the tails of distributions, we use the following $n-1$ points: $\frac{1}{n+1}, \frac{2}{n+1}, \frac{3}{n+1} \ldots \frac{n-1}{n+1}$ or $\frac{2}{n+1}, \frac{3}{n+1}, \frac{4}{n+1} \ldots \frac{n}{n+1} \cdot{ }^{10}$ to discretize continuous variables into $n$ states. The model's performance with continuous variables discretized into various states is tested using the ten-fold analysis. Table 7 presents the model's average performance in the ten test samples.

${ }^{10}$ If bankrupt firms tend to have extreme values at the left tails of variables, $\frac{1}{n+1}, \frac{2}{n+1}, \frac{3}{n+1} \ldots \frac{n-1}{n+1}$ are used to discretize them $(M, R, C H, L M, C H N)$, while if bankrupt firms tend to have extreme values at the right tails of the variable $(I F R), \frac{2}{n+1}, \frac{3}{n+1}, \frac{4}{n+1} \ldots \frac{n}{n+1}$. are used to discretize such variable. 
Insert Table 7 Here

When continuous variables are discretized into 2 states, the model's accuracy in predicting bankruptcy is $82.58 \%$, and its accuracy in predicting nonbankruptcy is $77.55 \%$. When the number of discretization states increases to 3, the model's accuracy in predicting bankruptcy is $83.37 \%$ and its accuracy in predicting non-bankruptcy is $77.44 \%$. Untabulated T-test results suggest that there is no significant difference in the model's performance between 2 states and 3 states. When the number of states increases to 4 , the model's accuracy in predicting bankruptcy is $83.82 \%$, which is statistically indifferent to the model's performance with 2 or 3 states. However, the model's accuracy in predicting nonbankruptcy is decreased to $74.94 \%$, which is significantly $(p<0.001)$ worse than that with 2 or 3 states. When we increase the number of states for discretization further, the model's performance continues to drop. With the 10 states of discretization, the model's accuracy in predicting bankruptcy is decreased to $80.67 \%$ (insignificantly different from that with 2 or 3 states), and its accuracy in predicting nonbankruptcy is decreased to only $69.46 \%$ (significantly $(p<0.001)$ worse than that with 2 or 3 states). To summarize, using a large training sample (on average 801 bankruptcies and 6,239 non-bankruptcies) and a naïve Bayes model in which 6 out of 8 predictor variables are continuous, we find that discretizing continuous variables into 2 or 3 states leads to the best performance. One possible interpretation of this finding is that bankrupt firms tend to have extreme values at one end of the distributions, while non-bankrupt firms tend to have extreme values at the opposite end. Two or three states are sufficient enough to capture the distinction. With four or more states, the model's performance significantly deteriorates, probably due to over-fitting. 


\subsection{Modeling Continuous Variables with Probability Density Functions}

The discretization of continuous variables has been criticized by researchers (Poland and Shachter 1993). For instance, Miller and Rice (1983) and Keefer (1992) note that representing continuous distributions accurately with a few points is tricky if the tails of the distributions are significant. Next instead of discretizing continuous variables $(M, R, L M, C H, C H N)$, we fit them using the normal distribution to see whether the prediction ability of the naïve Bayes model in Figure 3 can be improved. Note that we choose to discretize IFR here because the goodness-offit of the normal distribution for this variable is too low. One possible reason for the low goodness-of-fit is that, different from other variables that are firm specific, Industry failure rate, $I F R$, is an industry level factor. Again, the ten-fold analysis is used here. For each fold, we use the training sample to estimate the parameters (mean and standard deviation) of the normal distributions modeling continuous variables. The probability density function for each continuous variable given bankruptcy $(B)$ and that given non-bankruptcy $(N B)$ are then used to calculate the likelihood of bankruptcy given values of variables. Assuming that the prior of bankruptcy is unknown $\left(\frac{P(B)}{P(N B)}=1\right)$, the posterior likelihood of bankruptcy is calculated as:

$$
\begin{aligned}
& \text { Likelihood_Ratio }\left(\frac{B \mid A U, I T, I F R, M, R, L M, C H, C H N}{N B \mid A U, I T, I F R, M, R, L M, C H, C H N}\right) \\
& =\frac{P(A U \mid B)}{P(A U \mid N B)} \times \frac{P(I T \mid B)}{P(I T \mid N B)} \times \frac{P(I F R \mid B)}{P(I F R \mid N B)} \times \frac{f(M \mid B)}{f(M \mid N B)} \\
& \times \frac{f(R \mid B)}{f(R \mid N B)} \times \frac{f(L M \mid B)}{f(L M \mid N B)} \times \frac{f(C H \mid B)}{f(C H \mid N B)} \times \frac{f(C H N \mid B)}{f(C H N \mid N B)}
\end{aligned}
$$

The right column of Table 8 presents the ten-fold analysis result when modeling five continuous variables $(M, R, L M, C H, C H N)$ using normal distributions. For comparison purposes, the left column of Table 8 shows the model's performance when continuous variables 
are discretized into three discrete states under the EP-T method. Untabulated T-test results suggest that compared to discretizing continuous variables into 3 states, modeling them with normal distributions leads to a statistically indifferent performance in predicting bankruptcy $(83.60 \%$ vs. $81.13 \%)$, but a statistically significantly $(p<0.001)$ worse performance in predicting nonbankruptcy $(77.51 \%$ vs. $81.85 \%)$. One possible explanation for this finding is that the normal distribution does not represent the underlying distributions of empirical data very well because financial ratios tend to be skewed (e.g., Karels and Prakash 1987). We also experimented to identify and use the best-fit distributions for continuous variables using Crystal Ball software ${ }^{11}$. The results are substantially similar to those using the normal distribution. Again, it is possible that even the best-fit distributions do not represent the underlying distribution of the real world data very well. This finding provides some justification for discretizing continuous variables in the context of bankruptcy prediction.

Insert Table 8 Here

\subsection{Naïve Bayes vs. Logistic Regression}

In this section, we compare the performance of the naïve Bayes model in Figure 3 with that of logistic regression, a widely used bankruptcy prediction tool. Since logistic regression is not applicable to observations with missing data unless proper techniques are used to estimate the missing values, this comparison ${ }^{12}$ is restricted to firms with complete information on the eight

\footnotetext{
${ }^{11}$ Crystal Ball software selected the following distributions for our experiment: Normal, Inverse Gaussian, Pareto, and Error Function, among a potential pool of 14 distributions, including Beta, Exponential, Extreme Value, Logistic, Log-Logistic, Lognormal, Pearson Type V, Triangular, Uniform, and Weibull.

${ }^{12}$ We also experimented the stepwise logistic regression at a selection criterion of $p=0.05$ (Jones 1987). In order to enter the stepwise logistic regression, a sample firm needs to have complete information on all twenty potential predictors used in this study. This restriction further reduces the sample to 304 bankruptcies and 1,151
} 
predictors in Figure 3. Thus, the study sample is reduced to 414 bankruptcies and 1,435 nonbankruptcies. Given the small sample size, a five-fold analysis is performed. Using the same eight variables presented in Figure 3, logistic regression has an average prediction rate of $79.48 \%$ in bankruptcy sample, and $82.02 \%$ in non-bankruptcy sample. The naïve Bayes model in Figure 3 has an average prediction rate of $80.43 \%$ in bankruptcy sample, and $80.00 \%$ in non-bankruptcy sample. Untabulated T-tests suggest that there is no significant difference (at the $5 \%$ level of significance) between two models' performance. The estimation ${ }^{13}$ of logistic regression is as follows:

$$
\begin{aligned}
y & =-4.755+0.933 A U+1.098 I T-3.165 C H-0.056 L M-2.222 R-0.391 C H N+0.356 I F R \\
& -0.156 M
\end{aligned}
$$

where $y=\ln \frac{B}{1-B}$.

It is important to note that the naïve Bayes model is able to achieve an equivalent level of performance in a sub-sample of firms with missing data (See Panel B of Table 6), to which logistic regression is not applicable unless certain techniques of filling missing data is employed.

nonbankruptcies. The stepwise logistic regression is estimated as:

$$
\begin{aligned}
y & =-11.678+0.881 A U+0.661 I T-0.219 L M-1.452 R+0.205 I F R-0.728 M+1.377 T L \\
& -0.564 E+0.701 T A
\end{aligned}
$$

where $y=\ln \frac{B}{1-B}$. Stepwise logistic regression selects nine predictors, six of which are the same as those used in the naïve Bayes model in Figure 3. Based upon a five-fold analysis, logistic regression has an average prediction rate of $84.20 \%$ in bankruptcy sample, and $84.10 \%$ in non-bankruptcy sample. For the same sample of firms, the naïve Bayes model has a prediction rate of $81.90 \%$ and $80.20 \%$. Untabulated T-tests suggest that there is no significant difference (at the 5\% level of significance) between two models' performance.

${ }^{13}$ Estimations of coefficients reported here are the averages of coefficient values in five regressions obtained in fivefold analysis. 


\section{SUMMARY AND CONCLUSIONS}

In this study, we examine several important methodological issues related to the use of naïve Bayes Bayesian network (BN) models to predict bankruptcy. None of these issues have been studied by existing literature. First, we provide a heuristic method that guides the selection of predictor variables from a pool of potential variables. This method is very easy to implement and proves to be effective by the empirical results. Under this method, only variables that have significant correlations with the variable of interest, the status of bankruptcy, are selected. As a result, 8 variables are selected from a pool of 20 potential predictors. Based on a ten-fold analysis, the naïve $\mathrm{BN}$ consisting of these 8 selected variables have an average prediction accuracy of $81.12 \%$ for the bankruptcy sample and $81.85 \%$ for the non-bankruptcy sample. This prediction accuracy is appealing given the difficulty nature of bankruptcy prediction and is comparable to results reported by some other studies (e.g. Ohlson 1980; Hopwood et al. 1994; McKee and Greenstein 2000; McKee and Lensberg 2002) in this domain (see Table 9).

Insert Table 9 Here

Bankruptcy prediction often involves incomplete information on some predictors. We further discuss how to select second-order variables that can compensate for missing information on selected predictors. Our empirical evidence does not show a significant improvement upon models' performance by incorporating second-order variables. Similar results are observed even after we restrict sample firms to those with at least 2 first-order variables missing. Nevertheless, our results do not deny the possible superiority of the cascaded model over the naïve model in situations where missing information on first-order variables are even more substantial. 
Second, we investigate the impact on a naïve Bayes model's performance of the number of states into which continuous variables are discretized. The naïve Bayes model consists of eight variables, six of which are continuous. Using an average training sample size of 801 bankruptcies and 6,239 non-bankruptcies, we find that the model's performance is the best with the six continuous variables being discretized into 2 or 3 states. When the number of states is increased to 4 or more, the model's performance deteriorates, probably due to over-fitting.

Finally, we compare the performance of the naïve Bayes model with continuous variables being discretized and the performance of the model with continuous variables being modeled with normal distributions. Our results show that replacing discretization with probability density functions does not increase the model's performance. On the contrary, modeling continuous variables with normal distributions leads to a significant decrease in predicting nonbankruptcy sample. We also experimented to identify and use the best-fit distributions for continuous variables. The results are substantially similar to those using the normal distribution. One potential explanation is that normal distributions (or even the best-fit distributions) do not represent variables' underlying distributions very well.

More importantly, the above reported results could also be applicable to contexts other than bankruptcy prediction. Of course, the study has its limitations, some of which imply the need for additional research. Based upon this study's results, we can conclude that our proposed heuristic for variable selection is simple to implement and performs well. However, this study does not examine the relative performance of the proposed heuristic compared to other correlation-based algorithm (e.g. Hall 1999). This is a limitation of our paper which desires some future research. This study adapts the extended Pearson-Tukey (EP-T) method (Keefer and Bodily 1983), a method of three-point approximations, to convert continuous variables into 
discrete. According to Keefer (1994), the EP-T method is one of those three-point discretedistribution approximations that accurately represent certainty equivalents for continuous random variables. However, we do not test the relative performance of the EP-T method compared to other discretization methods as proposed in machine learning literature (e.g., Fayyad and Irani 1992). Future research is useful to do such a comparison. Various variable selection algorithms have been developed/utilized for other bankruptcy prediction techniques, such as genetic algorithms for neural networks (Back, Laitinen, and Sere 1996). It is interesting future research to explore how these algorithms can be applied into $\mathrm{BN}$ models.

In addition, the sample proportion of bankruptcies used in this study is larger than the realistic population proportion of bankruptcies, which leads to the ignorance of the prior during our study process. There are other important bankruptcy predictors which are not examined by the study. Finally, this study focuses on only one type of BN models: naïve Bayes. Future research is also needed to explore how to better apply other types of BN models, such as noisyOR (Vomlel 2003), to bankruptcy prediction.

\section{Acknowledgements}

We are grateful for Roman Slowinski, the editor, and five anonymous referees for their constructive comments on earlier versions of this paper.

\section{REFERENCES}

Altman, E. 1968. Financial Ratios, Discriminant Analysis and the Prediction of Corporate Bankruptcy. The Journal of Finance 23 (September): 589-609

Altman, E., R. Haldeman, and P. Narayanan, 1977. Zeta Analysis: A New Model to Identify Bankruptcy Risk of Corporations. Journal of Banking and Finance 10: 29-54 
Altman, E., G. Marco, and F. Varetto. 1994. Corporate Distress Diagnosis: Comparisons Using Linear Discriminant Analysis and Neural Networks. Journal of Banking and Finance 18: 505-29.

Anderson, R. D., R. D. Mackoy, V. B. Thompson, and G. Harrell. 2004. A Bayesian Network Estimation of the Service-Profit Chain for Transport Service Satisfaction. Decision Sciences 35 (4): 665-690.

Barth, M., W. Beaver, and W. Landsman. 1998. Relative Valuation Roles of Equity Book Value and Net Income as a Function of Financial Health. Journal of Accounting and Economics 25: $1-34$.

Back B., T. Laitinen, and K. Sere. 1996. Neural Networks and Genetic Algorithms for Bankruptry Prediction. Expert Systems with Applications, An International Journal 11 (4): 407-413.

Beaver, W. H. 1966. Financial Ratios as Predictors of Failure. Journal of Accounting Research 4 (supplement): 71-111.

Begley, J., J. Ming, and S. Watts. 1996. Bankruptcy Classification Errors in the 1980s: An Empirical Analysis of Altman's and Ohlson's Models. Review of Accounting Studies 1 (4): 267-84

Clark, P., and T. Niblett. 1989. The CN2 Induction Algorithm. Machine Learning, 3, 261-283.

Emery, G. W., and K.O. Cogger. 1982. The Measurement of Liquidity. Journal of Accounting Research 20 (Autumn): 290-303.

Fayyad, U.M., and K.B. Irani. 1992. On the Handling of Continuous-valued Attributes in Decision Tree Generation, Machine Learning, 8, 87-102.

Hall, M.A. 1999. Correlation-based Feature Selection for Machine Learning, PhD thesis, University of Waikato.

Hopwood, W.S., J.C. Mckeown, and J.P. Mutchler. 1989. A Test of the Incremental Explanatory Power of Opinions Qualified for Consistency and Uncertainty. The Accounting Review 64 (January): 28-48.

Hopwood, W.S., J.C. Mckeown, and J.P. Mutchler. 1994. A Reexamination of Auditor Versus Model Accuracy within the Context of the Going Concern Opinion Decision. Contemporary Accounting Research 10 (Spring): 409-431.

Jones, F. 1987. Current Techniques in Bankruptcy Prediction, Journal of Accounting Literature 6: 131-164.

Karels, G.V., and A. J. Prakash. 1987. Multivariate normality and forecasting of business bankruptcy. Journal of Business Finance \& Accounting 14 (4): 573-593. 
Keefer, D. L. 1992. Certainty Equivalents for Three-Point Discrete-Distribution Approximations. Working paper, Department of Decision and Information Systems, Arizona State University, Tempe, AZ.

Keefer, D. L. 1994. Certainty Equivalents for Three-Point Discrete-Distribution Approximations. Management Science 40 (6): 760-773.

Keefer, D. L., and S. E. Bodily. 1983. 3-Point Approximations for Continuous Random Variables. Management Science 29: 595-609.

Koller, D. and M. Sahami, Toward Optimal Feature Selection, Proceedings of the Thirteenth International Conference in Machine Learning, Morgan Kaufmann Publishers, San Francisco, CA. 1996, 284-292.

Kononenko, I. 1990. Comparison of Inductive and Naive Bayesian Learning Approaches to Automatic Knowledge Acquisition. In B. Wielinga (Ed.), Current Trends in Knowledge Acquisition. Amsterdam, The Netherlands: IOS Press.

Kotsiantis, S., D. Tzelepis, E. Koumanakos, and V. Tampakas. 2005. Efficiency of Machine Learning Techniques in Bankruptcy Prediction. 2nd International Conference on Enterprise Systems and Accounting, Thessaloniki, Greece.

Langley, P., W. Iba, and K. Thompson, 1992. An Analysis of Bayesian Classifiers. Proceedings of the Tenth National Conference on Artificial Intelligence: 223-228. San Jose, CA: AAAI Press.

McKee, T.E. 1998. A Mathematically Derived Rough Set Model for Bankruptcy Prediction. In Collected Papers of the Seventh Annual Research Workshop on Artificial Intelligence and Emerging Technologies in Accounting, Auditing and Tax, Brown CE (ed.). Artificial Intelligence/Emerging Technologies Section of the American Accounting Association.

McKee, T.E, and M. Greenstein. 2000. Predicting Bankruptcy Using Recursive Partitioning and a Realistically Proportioned Data Set. Journal of Forecasting 19: 219-230.

McKee, T.E, and T. Lensberg. 2002. Genetic Programming and Rough Sets: A Hybrid Approach to Bankruptcy Classification. European Journal of Operational Research 138: 436-451.

McKee, T.E. 2003. Rough Sets Bankruptcy Prediction Models versus Auditor Signaling Rates. Journal of Forecasting 22: 569-586.

Miller, A. C., and T. R. Rice. 1983. Discrete Approximations of Probability Distributions. Management Science 29: 352-362.

Ohlson, J. A. 1980. Financial Ratios and the Probabilistic Prediction of Bankruptcy. Journal of Accounting Research 19: 109-131. 
Pazzani, M., J. Muramatsu, and D. Billsus. 1996. Syskill \& Webert: Identifying Interesting Web Sites. Proceedings of the Thirteenth National Conference on Artificial Intelligence: 54-61. Portland, OR: AAAI Press.

Pearl, J. 1988. Probabilistic Reasoning in Intelligent Systems. Morgan Kaufmann.

Poland, W. B, and R. D. Shachter. 1993. Mixtures of Gaussians and Minimum Relative Entropy Techniques. In Uncertainty in Artificial Intelligence: Proceedings of the Ninth Conference: 183-190. San Mateo, CA: Morgan Kaufmann.

Sarkar, S., and R. S. Sriram. 2001. Bayesian Models for Early Warning of Bank Failures. Management Science, 47 (11): 1457-1475.

Senetti, J. T. 1995. On the Incoherent Use of Evidence: Why Subjective Bayesian Evidence Is Not Held Probative. Auditing: A Journal of Practice and Theory 13: 193-199.

Shumway, T. 2001. Forecasting Bankruptcy More Accurately: A Simple Hazard Model. The Journal of Business 74: 101-124.

Tam, K.Y. and M.Y. Kiang. 1992. Managerial Applications of Neural Networks: The Case of Bank Failure Predictions. Management Science 38(7): 926-947.

Titterington, D. M, G. D. Murray, L. S. Murray, D. J. Spiegelhalter, A. M. Skene, J. D. F. Habbema, and G. J. Gelpke. 1981. Comparison of Discrimination Techniques Applied to a Complex Data-set of Head-injured Patients (with discussion). Journal of the Royal Statistical Society, Series A, 144, 145-175.

Vomlel, J. 2003. Noisy-OR Classifier. Proceedings of the Sixth Workshop on Uncertainty Processing, 291-302.

Zmijewski, M. 1984. Methodological Issues Related to the Estimation of Financial Distress Prediction Models. Journal of Accounting Research 22 (Supplement): 59-82. 
Table 1: Definitions of Potential Predictor Variables

\begin{tabular}{|c|c|c|c|}
\hline \multirow{17}{*}{ 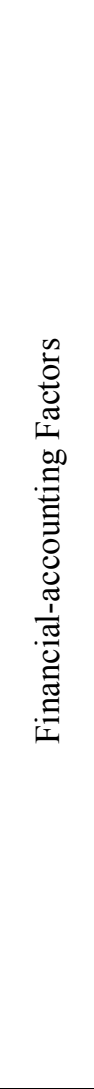 } & Construct & Name & Definition \\
\hline & Size & $T A$ & $\begin{array}{l}\text { Natural log of (Total Assets/ GNP Implicit Price Deflator Index). The index assumes a base value of } 100 \text { for } \\
1968 .\end{array}$ \\
\hline & \multirow{6}{*}{ Liquidity } & $W$ & (Current Assets - Current Liabilities)/Total Assets \\
\hline & & $C R$ & Current Assets/ Current Liabilities \\
\hline & & OF & Operating Cash Flows /Total Liabilities \\
\hline & & $L M$ & $\begin{array}{l}(L+\mu) / \sigma . L=\text { cash }+ \text { short-term marketable securities, } \mu=\text { mean, } \sigma=\text { standard deviation of quarter-to-quarter } \\
\text { change in } L \text { over prior } 12 \text { quarters }\end{array}$ \\
\hline & & $C A$ & Current Assets/Total Assets \\
\hline & & $\mathrm{CH}$ & Cash/Total Assets \\
\hline & \multirow{2}{*}{ Leverage } & $T L$ & (Total Liabilities/Total Assets) x 100\% \\
\hline & & $L T D$ & Long Term Debts/Total Assets \\
\hline & \multirow{2}{*}{ Turnover } & $S$ & Sales/Total Assets \\
\hline & & $C S$ & Current Assets/Sales \\
\hline & \multirow{5}{*}{ Profitability } & $E$ & Earnings before Interest and Taxes/Total Assets \\
\hline & & $N T$ & Net income/Total assets \\
\hline & & $I T$ & One if net income was negative for the last two years, else zero \\
\hline & & $R E$ & Retained Earnings/Total Assets \\
\hline & & $\mathrm{CHN}$ & (Net income in year $\mathrm{t}-$ Net income in $\mathrm{t}-1) /($ Absolute net income in year $\mathrm{t}+$ Absolute net income in year $\mathrm{t}-1)$ \\
\hline \multirow{2}{*}{\multicolumn{2}{|c|}{ Market-Based Factors }} & $M$ & natural log of each firm's size relative to the CRSP NYSE/AMEX/NASDAQ market capitalization index \\
\hline & & $R$ & $\begin{array}{l}\text { the firm's stock return in year } \mathrm{t}-1 \text { minus the value-weighted CRSP NYSE/AMEX/NASDAQ index return in } \\
\text { year } \mathrm{t}-1\end{array}$ \\
\hline \multirow{2}{*}{\multicolumn{2}{|c|}{ Other Factors }} & $A U$ & $\begin{array}{l}A U=\text { Zero if Compustat codes auditors" opinions as "1.unqualified"; } A U=\text { One if Compustat codings are "0. } \\
\text { unaudited"; "2.qualified"; "3. no opinion"; "4.unqualified with additional language"; "5.adverse opinion". }\end{array}$ \\
\hline & & $I F R$ & $\begin{array}{l}\text { Industry failure rate, calculated as the average bankruptcy rate in the past two years, where bankruptcy rate }= \\
\text { ( the number of bankruptcies in a two-digit SIC industry } \div \text { the total number of firms in the same industry }) \times \\
100 \%\end{array}$ \\
\hline
\end{tabular}


Table 2: Descriptive Statistics

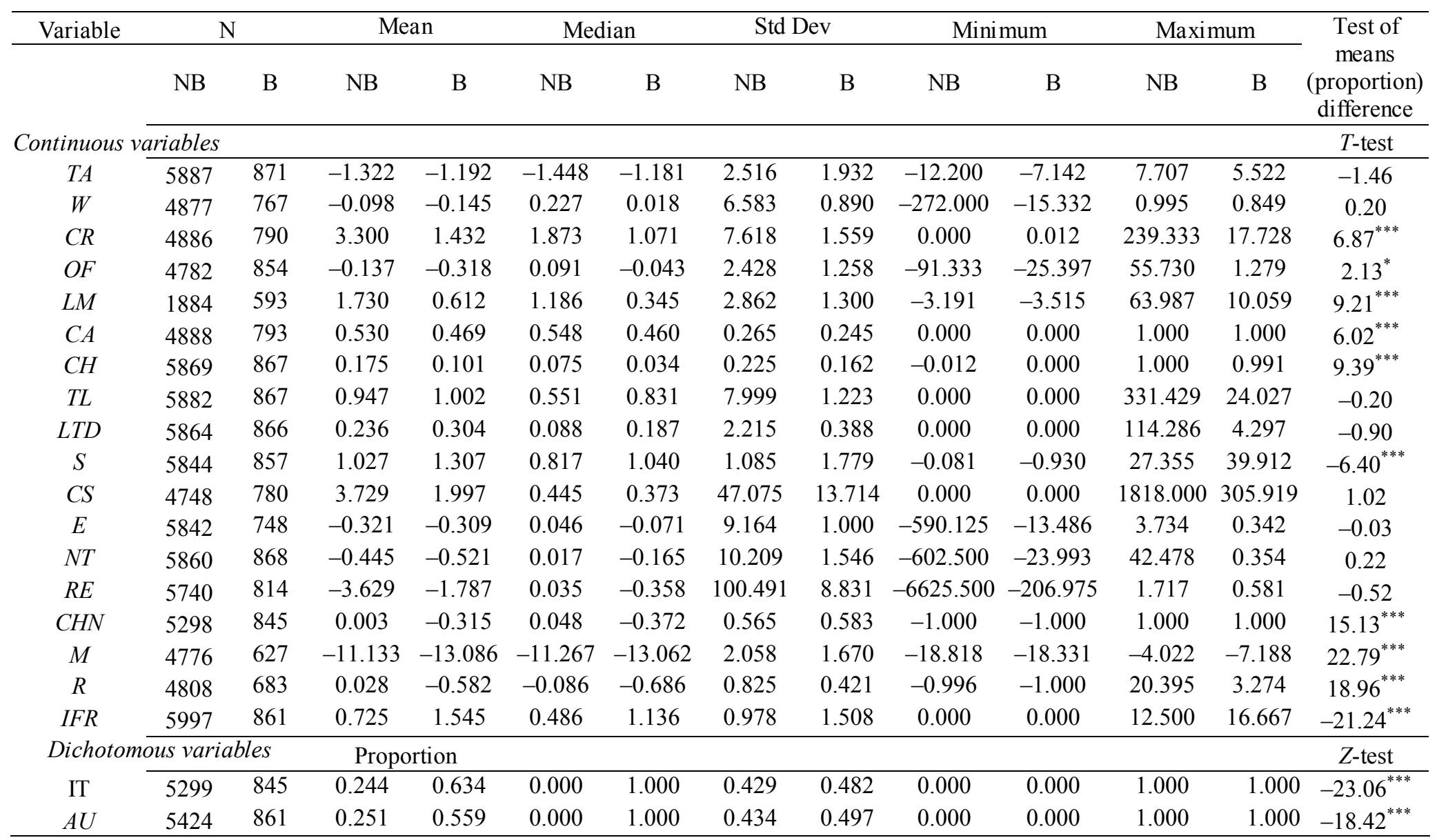

${ }^{*}$ Significant at $\mathrm{p}$-value $<0.05 ;{ }^{* *}$ Significant at $\mathrm{p}$-value $<0.01 ;{ }^{* * *}$ Significant at $\mathrm{p}$-value $<0.001$ 


\section{Table 3:}

Average Annual Percentage of Bankruptcies by Two-digit SIC during the Entire Study Period

\begin{tabular}{llc}
\hline \multicolumn{1}{c}{ Industry } & \multicolumn{1}{c}{ Primary SIC code } & $\begin{array}{c}\text { Average Industry } \\
\text { Failure Rate }\end{array}$ \\
\hline 0. Agriculture, forestry, and fisheries & $0100-0999$ & \\
1. Mining and Construction & $1000-1999$ except for 1300-1399 & $0.78 \%$ \\
2. Food & $2000-2111$ & $1.10 \%$ \\
3. Textiles, printing and publishing & $2200-2799$ & $0.81 \%$ \\
4. Chemicals & $2800-2824$, and $2840-2899$ & $1.45 \%$ \\
5. Pharmaceuticals & $2830-2836$ & $0.52 \%$ \\
6. Extractive industries & $2900-2999$, and $1300-1399$ & $0.18 \%$ \\
7. Durable manufacturers & $3000-3999$, except 3570-3579, and 3670- & $0.68 \%$ \\
& 3679 & $0.82 \%$ \\
8. Computers & $7370-7379,3570-3579$, and 3670-3679 & $0.80 \%$ \\
9. Transportation & $4000-4899$ & $1.58 \%$ \\
10. Utilities & $4900-4999$ & $0.74 \%$ \\
11. Retail & $5000-5999$ & $1.94 \%$ \\
12. Financial institutions & $6000-6411$ & $0.33 \%$ \\
13. Insurance and real estate & $6500-6999$ & $0.18 \%$ \\
14. Services & $7000-8999$, except 7370-7379 & $1.14 \%$ \\
15. Other & $>9000$ & $1.13 \%$ \\
\hline
\end{tabular}


Table 4: Partial Correlations

Panel A: Selection of First-order Variables

\begin{tabular}{lll}
$\begin{array}{l}\text { Pair } \\
\text { No. }\end{array}$ & \multicolumn{2}{c}{ Partial Correlation } \\
\hline 1 & $\operatorname{Corr}(B, C H \mid L M)=-0.10$, & $\operatorname{Corr}(B, L M \mid C H)=-0.13 ;$ \\
2 & $\operatorname{Corr}(B, C H \mid I T)=-0.19$, & $\operatorname{Corr}(B, I T \mid C H)=0.33 ;$ \\
3 & $\operatorname{Corr}(B, C H \mid A U)=-0.11$, & $\operatorname{Corr}(B, A U \mid C H)=0.22 ;$ \\
4 & $\operatorname{Corr}(B, L M \mid M)=-0.13$, & $\operatorname{Corr}(B, M \mid L M)=-0.31 ;$ \\
5 & $\operatorname{Corr}(B, L M \mid A U)=-0.13$, & $\operatorname{Corr}(B, A U \mid L M)=-0.30 ;$ \\
6 & $\operatorname{Corr}(B, I T \mid C H N)=0.28$, & $\operatorname{Corr}(B, C H N \mid I T)=-0.17 ;$ \\
7 & $\operatorname{Corr}(B, I T \mid I F R)=0.28$, & $\operatorname{Corr}(B, I F R \mid I T)=0.22 ;$ \\
8 & $\operatorname{Corr}(B, I T \mid R)=0.29$, & $\operatorname{Corr}(B, R \mid I T)=-0.22 ;$ \\
9 & $\operatorname{Corr}(B, I T \mid M)=0.22$, & $\operatorname{Corr}(B, M \mid I T)=-0.22 ;$ \\
10 & $\operatorname{Corr}(B, I T \mid L M)=0.32$, & $\operatorname{Corr}(B, L M \mid I T)=-0.12 ;$ \\
11 & $\operatorname{Corr}(B, I T \mid A U)=0.25$, & $\operatorname{Corr}(B, A U \mid I T)=0.19 ;$ \\
12 & $\operatorname{Corr}(B, M \mid R)=-0.26$, & $\operatorname{Corr}(B, R \mid M)=-0.19 ;$ \\
13 & $\operatorname{Corr}(B, C H N \mid R)=-0.22$, & $\operatorname{Corr}(B, C H N \mid R)=-0.14 ;$ \\
\hline
\end{tabular}

Panel B: Selection of Second-order Variables

B.1: Selection of second-order variables for $\mathrm{CH}$

\begin{tabular}{lll}
\hline 14 & $\operatorname{Corr}(C H, O F \mid C R)=-0.04$, & $\operatorname{Corr}(C H, C R \mid O F)=0.34 ;$ \\
15 & Corr $(C H, O F \mid C S)=-0.22$, & $\operatorname{Corr}(C H, C S \mid O F)=0.12 ;$ \\
16 & $\operatorname{Corr}(C H, O F \mid T A)=-0.18$, & $\operatorname{Corr}(C H, T A \mid O F)=-0.25 ;$ \\
17 & $\operatorname{Corr}(C H, C R \mid C S)=0.42$, & $\operatorname{Corr}(C H, C S \mid C R)=0.08 ;$ \\
18 & $\operatorname{Corr}(C H, C R \mid T A)=0.38$, & $\operatorname{Corr}(C H, T A \mid C R)=-0.23 ;$ \\
19 & $\operatorname{Corr}(C H, C R \mid C A)=0.34$, & $\operatorname{Corr}(C H, C A \mid C R)=0.52 ;$ \\
20 & $\operatorname{Corr}(C H, S \mid C R)=-0.16$, & $\operatorname{Corr}(C H, C R \mid S)=0.38 ;$ \\
21 & $\operatorname{Corr}(C H, T A \mid C A)=-0.11$, & $\operatorname{Corr}(C H, C A \mid T A)=0.52 ;$ \\
22 & $\operatorname{Corr}(C H, T A \mid S)=-0.31$, & $\operatorname{Corr}(C H, S \mid T A)=-0.21 ;$ \\
23 & $\operatorname{Corr}(C H, C A \mid S)=0.63$, & $\operatorname{Corr}(C H, S \mid C A)=-0.41 ;$ \\
\hline
\end{tabular}

B.2: Selection of second-order variables for $L M$

$24 \quad \operatorname{Corr}(L M, C R \mid S)=0.31, \quad \operatorname{Corr}(L M, S \mid C R)=-0.03$;

B.3: Selection of second-order variables for $I T$

$25 \operatorname{Corr}(I T, O F \mid T A)=-0.04, \quad \operatorname{Corr}(I T, T A \mid O F)=0.06$

B.4: Selection of second-order variables for $M$

\begin{tabular}{lll}
26 & $\operatorname{Corr}(M, O F \mid T A)=0.02$, & $\operatorname{Corr}(M, T A \mid O F)=0.72 ;$ \\
27 & $\operatorname{Corr}(M, O F \mid C A)=0.14$, & $\operatorname{Corr}(M, C A \mid O F)=-0.15$ \\
28 & $\operatorname{Cor}(M, T A \mid C A)=0.72$, & $\operatorname{Cor}(M, C A \mid T A)=0.16$ \\
29 & $\operatorname{Corr}(M, T A \mid E)=0.69$, & $\operatorname{Corr}(M, E \mid T A)=0.11$ \\
30 & $\operatorname{Corr}(M, T A \mid N T)=0.69$, & $\operatorname{Corr}(M, N T \mid T A)=0.12$ \\
31 & $\operatorname{Cor}(M, T A \mid R E)=0.68$, & $\operatorname{Cor}(M, R E \mid T A)=0.03$ \\
32 & $\operatorname{Corr}(M, E \mid N T)=0.15$, & $\operatorname{Corr}(M, N T \mid E)=0.02$ \\
33 & $\operatorname{Corr}(M, E \mid R E)=0.16$, & $\operatorname{Cor}(M, R E \mid E)=0.10$ \\
34 & $\operatorname{Corr}(M, R E \mid N T)=0.14$, & $\operatorname{Corr}(M, N T \mid R E)=0.10$ \\
\hline
\end{tabular}


Table 5: Prediction Ability in the Test Sample

\begin{tabular}{c|cc|cc}
\hline & $\begin{array}{c}\text { The naïve Bayesian in Figure } 4 \text { with } 8 \\
\text { selected variables }\end{array}$ & \multicolumn{2}{c}{ The naïve Bayesian with all 20 potential } \\
variables
\end{tabular}

Table 6: Prediction Ability in the Test Sample for the Cascaded Naïve Bayes Model in Figure 4

Panel A: Average performance in ten-fold analysis using the full sample

$\begin{array}{ccc} & \% \text { bpt correct } & \% \text { nbpt correct } \\ \text { Cascaded } & 81.12 \% & 80.08 \% \\ \text { Naïve } & 81.12 \% & 81.85 \% \\ \text { T-test } & 0.000 & 2.101^{*}\end{array}$

Panel B: Average performance in five-fold analysis using the sample with two or more missing values on first-order variables

\begin{tabular}{ccc} 
& $\%$ bpt correct & $\%$ nbpt correct \\
Cascaded & $77.74 \%$ & $81.09 \%$ \\
Naïve & $77.36 \%$ & $83.80 \%$ \\
T-test & 0.081 & $1.860^{*}$ \\
\hline
\end{tabular}

* significant at $\mathrm{p}<0.05$ 
Table 7: The Effect of Number of States for Discretizing Continuous Variables

\begin{tabular}{ccc}
\hline \multirow{2}{*}{$\begin{array}{c}\text { \# states for } \\
\text { discretization }\end{array}$} & \multicolumn{2}{c}{ Average performance in the ten-fold analysis } \\
\hline 2 & 8 bpt correct & $\%$ non-bpt correct \\
\hline 3 & $83.58 \%$ & $77.55 \%$ \\
4 & $83.82 \%$ & $77.44 \%$ \\
5 & $83.37 \%$ & $74.94 \%$ \\
6 & $83.15 \%$ & $75.45 \%$ \\
7 & $82.25 \%$ & $73.83 \%$ \\
8 & $82.36 \%$ & $75.13 \%$ \\
9 & $81.57 \%$ & $72.36 \%$ \\
10 & $80.67 \%$ & $71.44 \%$ \\
\hline
\end{tabular}

Table 8: The Effect of Fitting Continuous Variables Using Normal Distribution

\begin{tabular}{c|cc|cc}
\hline & \multicolumn{2}{|c|}{$\begin{array}{c}\text { Discretizing Continuous } \\
\text { Variables }\end{array}$} & $\begin{array}{c}\text { Fitting Continuous Variables } \\
\text { Using Normal Distribution }\end{array}$ \\
\hline Test Set \#. & $\begin{array}{c}\text { \% bpt correct \% nbpt correct } \\
\% \text { bpt correct }\end{array}$ & $\%$ nbpt correct \\
\hline 1 & $79.78 \%$ & $82.25 \%$ & $79.78 \%$ & $78.64 \%$ \\
2 & $86.52 \%$ & $81.24 \%$ & $84.27 \%$ & $75.47 \%$ \\
3 & $78.65 \%$ & $82.56 \%$ & $86.52 \%$ & $78.53 \%$ \\
4 & $87.64 \%$ & $83.14 \%$ & $89.89 \%$ & $77.81 \%$ \\
5 & $74.16 \%$ & $83.69 \%$ & $83.15 \%$ & $80.09 \%$ \\
6 & $79.78 \%$ & $81.53 \%$ & $80.90 \%$ & $76.62 \%$ \\
7 & $85.39 \%$ & $77.06 \%$ & $86.52 \%$ & $71.28 \%$ \\
8 & $79.78 \%$ & $82.25 \%$ & $82.02 \%$ & $78.79 \%$ \\
9 & $79.78 \%$ & $82.40 \%$ & $82.02 \%$ & $78.21 \%$ \\
10 & $79.78 \%$ & $82.40 \%$ & $80.90 \%$ & $79.65 \%$ \\
\hline Average & $81.13 \%$ & $81.85 \%$ & $83.60 \%$ & $77.51 \%$ \\
\hline
\end{tabular}


Table 9: Bankruptcy Prediction Accuracy Rates Reported in some Prior Studies

\begin{tabular}{lcc}
\multicolumn{1}{c}{ Study } & $\begin{array}{c}\text { \% bpt } \\
\text { correct }\end{array}$ & $\begin{array}{c}\% \text { nbpt } \\
\text { correct }\end{array}$ \\
\hline Ohlson (1980) & $87.6 \%$ & $82.6 \%$ \\
Hopwood et al. (1994) [cost ratio of 50:1] & $70.3 \%$ & $83.3 \%$ \\
McKee and Greenstein (2000) & \multicolumn{2}{c}{$85 \%$} \\
McKee and Lensberg (2002) & \multicolumn{2}{c}{$80.3 \%$} \\
\hline
\end{tabular}


Figure 1: A Naïve Bayes BN Model

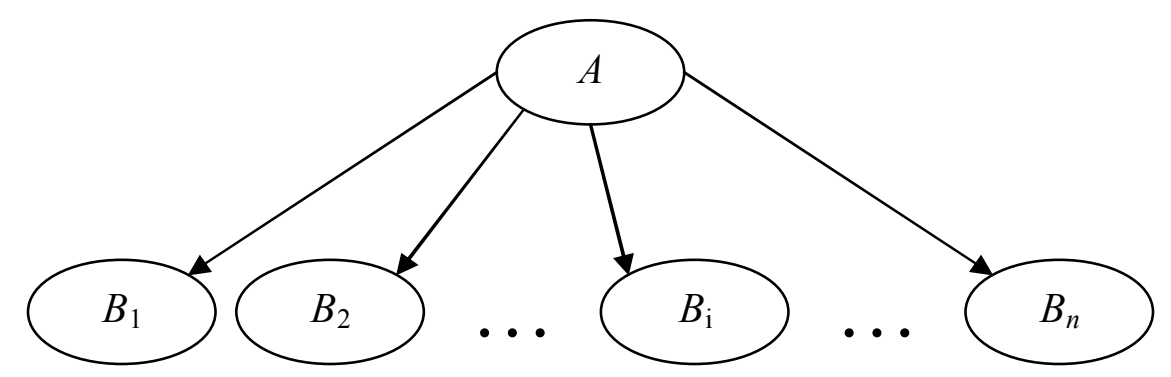

Figure 2: Dependencies Among the Variables

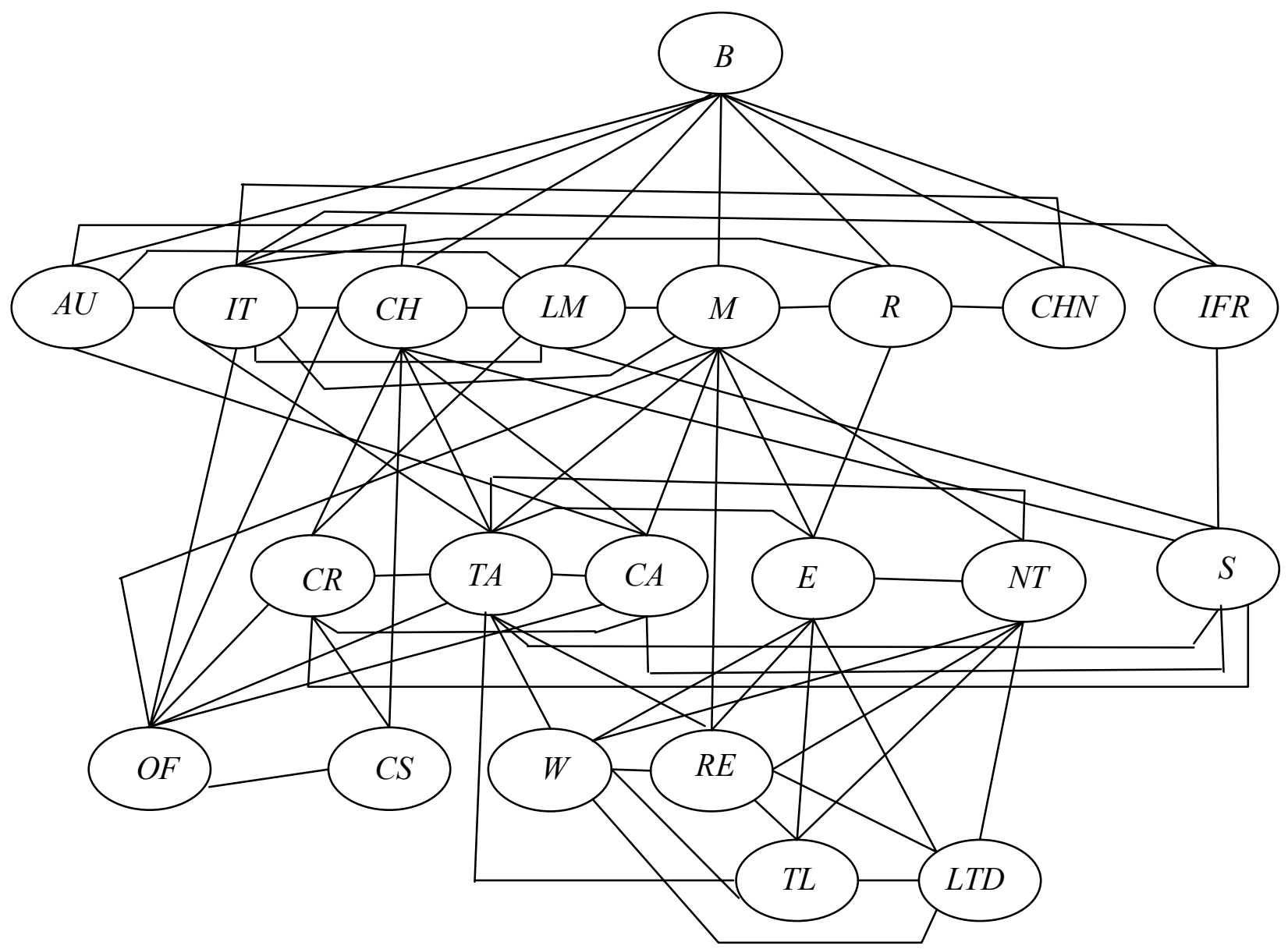


Figure 3: The Structure of the Naïve Bayes Model

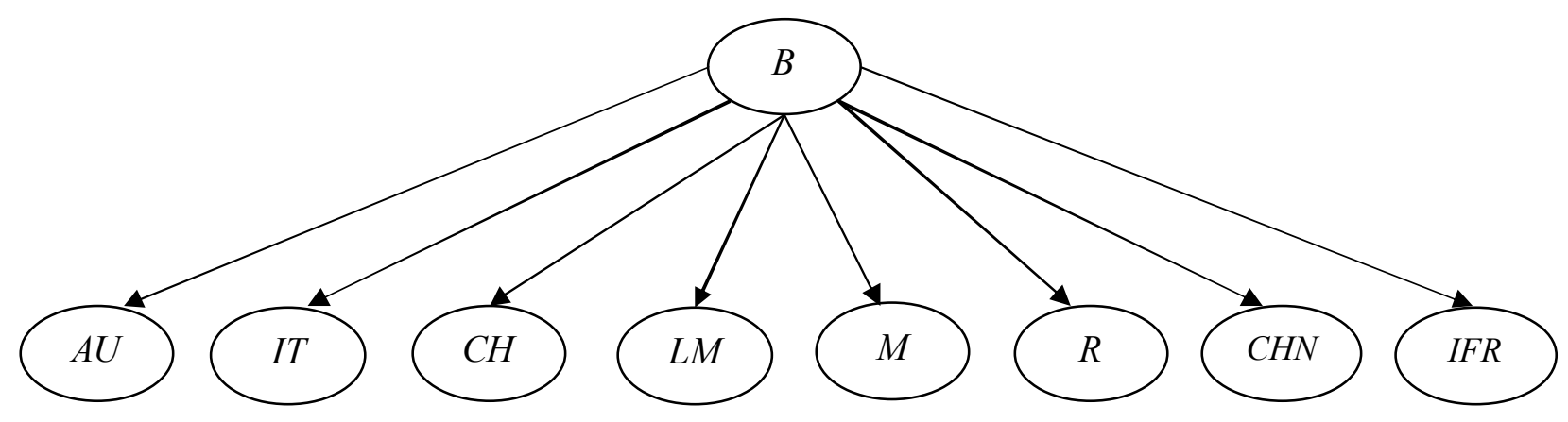

Figure 4: The Structure for the Cascaded Naïve Bayes Model with First and Second Order Variables.

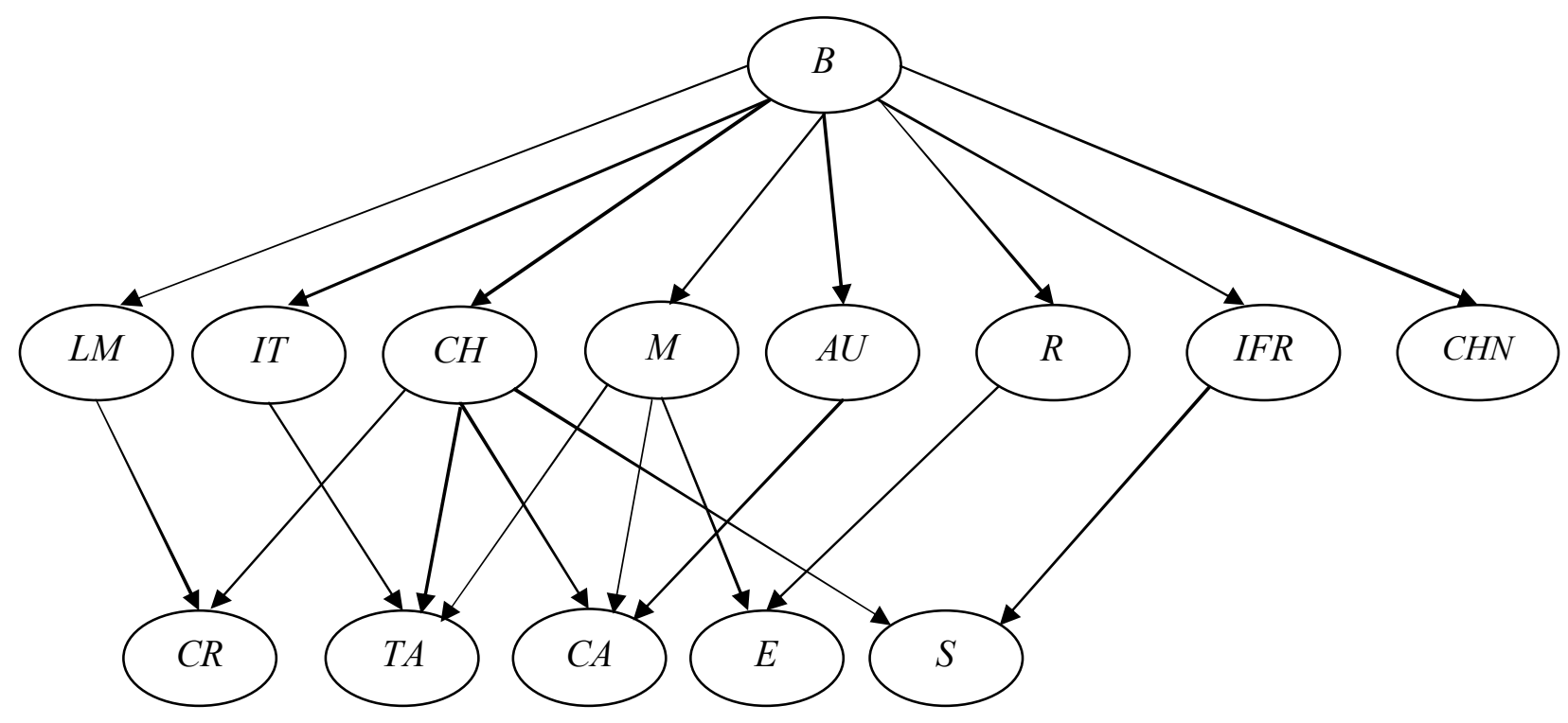


Appendix A: Conditional Probabilities Underlying the Naïve Bayes Model in Figure 3

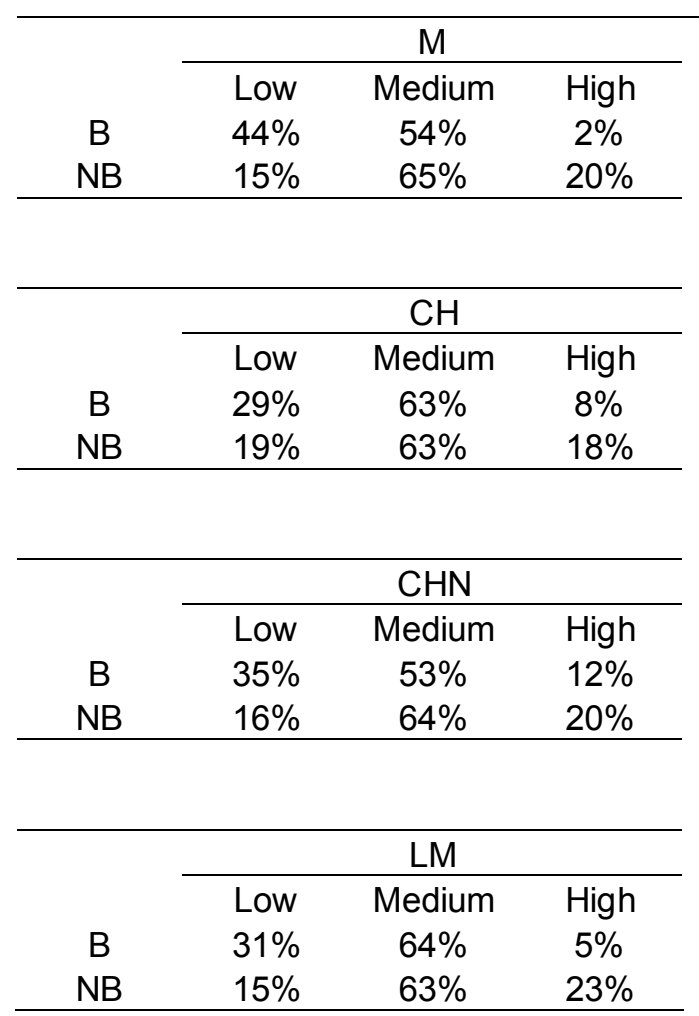

\begin{tabular}{|c|c|c|c|}
\hline & \multicolumn{2}{|c|}{$A U$} & \\
\hline & 1 & 0 & \\
\hline B & $56 \%$ & $44 \%$ & \\
\hline \multirow[t]{3}{*}{ NB } & $25 \%$ & $75 \%$ & \\
\hline & \multicolumn{2}{|c|}{$\mathrm{IT}$} & \\
\hline & 1 & 0 & \\
\hline$B$ & $63 \%$ & $37 \%$ & \\
\hline \multirow[t]{3}{*}{ NB } & $24 \%$ & $76 \%$ & \\
\hline & & IFR & \\
\hline & Low & Medium & High \\
\hline B & $9 \%$ & $69 \%$ & $22 \%$ \\
\hline \multirow[t]{3}{*}{ NB } & $19 \%$ & $75 \%$ & $6 \%$ \\
\hline & & $R$ & \\
\hline & Low & Medium & High \\
\hline B & $67 \%$ & $28 \%$ & $5 \%$ \\
\hline NB & $12 \%$ & $68 \%$ & $21 \%$ \\
\hline
\end{tabular}

